Diabetologia (1991) 34 [Suppl 1]: S21-S23

$0012186 \times 91001052$

\title{
The Stockholm experience with pancreatic transplantation using enteric exocrine diversion
}

\author{
G. Tydén ${ }^{1}$, A. Tibell ${ }^{1}$, J. Bolinder ${ }^{2}$, J. Östman ${ }^{2}$ and C.-G. Groth ${ }^{1}$ \\ Department of ${ }^{1}$ Transplantation Surgery and ${ }^{2}$ Medicine, Karolinska Institute, Huddinge Hospital, Stockholm, Sweden
}

\begin{abstract}
Summary. Between April 1974 and June 1990, 128 pancreatic transplantations were performed. Of these 117 were with pancreatico-enterostomy. In four consecutive series of combined transplantations in uraemic diabetic patients the 1-year graft survival rate have successively improved $(27 \%, 65 \%, 68 \%$ and $73 \%)$. In three similar series of single pancreatic transplantations the results also improved but still remained inferior $(0 \%, 33 \%$ and $33 \%)$. In a series of combined transplantations performed in preuraemic diabetic patients the 1-year actuarial graft survival rate was only $25 \%$. The results with pancreatic transplantation with pancreatico-enterostomy are now satisfactory. However, immunological loss graft function still constitute a major problem in the non- or preuraemic recipients. The metabolic control in patients with functioning grafts is normal or near-normal in the majority of patients followed for at least 1 year.
\end{abstract}

Key words: Pancreatic transplantation-Human-Enteric diversion.

\section{Introduction}

The results of pancreatic transplantation in the treatment of severe Type 1 (insulin-dependent) diabetes mellitus have recently shown a marked improvement. However, there is as yet no standard surgical procedure for pancreatic transplantation.

The most physiological technique is drainage of the exocrine secretion of the graft into the patient's bowel. When a pancreatic transplant program was initiated in Stockholm in 1974 we elected to drain the exocrine secretion into the patient's bowel by creating a pancreatico-enteric anastomosis (Groth et al. 1980). Initially this technique was associated with a high incidence of pancreatic fistulas. However, with refinements in the surgical technique and with the use of a pancreatic duct catheter for temporary protection of the pancreatico-enteric anastomosis the results became satis- factory. Furthermore, when pancreatico-duodenal grafts were introduced in 1988 the pancreatico-enteric anastomosis was replaced by a simple bowel-to-bowel anastomosis and the risk of enteric leakage has been more or less eliminated. We used enteric exocrine diversion in 117 of 128 pancreatic transplantations performed between April 1974 and June 1990. This report describes our experience with these transplantations.

\section{Subjects and methods}

Between April 1974 and June 1990, 128 pancreatic transplantations were performed at Huddinge Hospital. In four of the very early cases the pancreatic duct was simply ligated (Groth et al. 1976) and in seven transplantations performed between 1983 and 1984 the exocrine diversion was made to the patient's stomach (Tydén et al. 1985). These cases will not be discussed further.

Patients. Of the 107 diabetic patients, 10 underwent a second transplantation after the first had failed. All recipients suffered from Type 1 diabetes of long duration. Most of the transplantations were performed on uraemic diabetic patients; in 68 instances a combined renal and pancreatic transplantation was performed and in six instances the pancreatic transplantation was performed in a patient already having a renal graft. A further eight combined renal and pancreatic transplantations were performed in eight preuraemic recipients (mean creatinine $192 \mu \mathrm{mol} / \mathrm{l}$; range 164 $250 \mu \mathrm{mol} / \mathrm{l})$. In 31 instances single pancreatic transplantations were performed in 26 non- or pre-uraemic diabetic patients. The indications included hyperlabile diabetes with or without defective hormonal counterregulation (five patients), severe progressive angiopathy (one patient), rapidly progressing retinopathy (two patients), severe neuropathy (two patients) and preuraemic nephropathy (16 patients). In four patients scheduled for a combined renal and pancreatic transplantation, severe preservation damage of the pancreas was revealed following revascularization of the pancreatic graft and the grafts were removed peroperatively. Consequently, these cases are included in the single pancreas transplant group.

Surgical technique. In the recipients the graft artery and the graft portal vein were anastomosed end-to-side to the iliac vessels. In the first five cases a simple end-to-end 
pancreatico-Roux-en-Y loop enterostomy was created. In the following five transplantations a ducto-enterostomy was performed instead. All these grafts were placed extraperitoneally. However, because of technical problems with this technique, end-to-end pancreatico-enterostomy was reintroduced in 1981, but with some important modifications (Groth et al. 1982). Since then all grafts have been placed intraperitoneally. The cut end of the segmental grafts or the duodenum of pancreatico-duodenal grafts have mostly been anastomosed to a jejunal Roux-en-Y loop. However, in the most recent 18 cases with pancreatico-duodenal grafts the anastomosis was a simple side-to-side anastomosis between the donor duodenum and the recipient jejunum without the use of a Roux-en-Y loop. A catheter has been inserted into the pancreatic duct and then taken through the wall of the Rouxen-Y loop or the proximal part of the jejunum and brought out through a stab wound in the abdominal wall. By so doing we have temporarily exteriorized the pancreatic secretions, thus allowing the anastomosis to heal without being exposed to the digestive forces of the pancreatic exocrine secretion and also making the pancreatic secretions accessible for postoperative monitoring. The ductal catheter was removed 3-4 weeks after transplantation by simply pulling it out. Following this, the pancreatic secretions emptied into the recipient bowel.

\section{Results}

The series has been divided into five groups based on the period when the patients were treated (1974-1980; 1981$1983 ; 1984-1985 ; 1986-1987 ; 1988-1990)$. As shown in Table 1 considerable improvements in the overall results have occurred with time. When the series is divided into different patient categories, it is obvious that the best results have been obtained in uraemic diabetic recipients of combined renal and pancreatic grafts from the same donor. In the latest series of combined transplantations the 1-year patient and pancreatic survival rates are $82 \%$ and $73 \%$. With single pancreatic transplantation in nonuraemic recipients, the results have also improved, but only from poor to intermediate. In the first part of the segmental graft series the graft losses because of pancreatic fistula were approximately $13 \%$. This figure was reduced to $1 \%$ in the latest part of this series. With the use of pancreatico-duodenal grafts, there has been only one case of enteric leakage and this was not from the anastomosis but from the closed end of the duodenal segment.

Table 1. Results using pancreatic transplantation with enteric exocrine drainage in Stockholm, 1974-1990

$\begin{array}{clll} & \text { 1-year } & & \text { 1-year } \\ \text { patient } & & \text { graft } \\ \text { n } & \text { survival } & \text { n } & \text { survival }\end{array}$

All cases

$1974-80$

1981-83

$\begin{array}{rrrr}5 & 80 \% & 8 & 0 \% \\ 16 & 81 \% & 16 & 25 \% \\ 24 & 83 \% & 25 & 52 \%\end{array}$

$\begin{array}{lllll}1986-87 & 38 & 95 \% & 43 & 49 \% \\ 1988-90 & 24 & 87 \% & 25 & 49 \%\end{array}$

Combined renal and pancreatic

transplantation in uraemic diabetic patients

$\begin{array}{ccccc}1974-80 & 0 & 0 \% & 0 & 0 \% \\ 1981-83 & 15 & 80 \% & 15 & 27 \% \\ 1984-85 & 20 & 90 \% & 20 & 65 \% \\ 1986-87 & 21 & 100 \% & 22 & 68 \% \\ 1988-90 & 11 & 82 \% & 11 & 73 \%\end{array}$

Combined renal and pancreatic

transplantation in pre-uraemic patients

$\begin{array}{lllll}1987-88 & 7 & 100 \% & 8 & 25 \%\end{array}$

Single pancreatic transplantations in non-

or pre-uraemic diabetic patients

$\begin{array}{rrrrr}1974-85 & 7 & 71 \% & 10 & 0 \% \\ 1986-87 & 13 & 85 \% & 15 & 33 \% \\ 1988-90 & 6 & 83 \% & 6 & 33 \%\end{array}$

Pancreatic transplantation after

kidney transplantation

$\begin{array}{lllll}1974-87 & 4 & 75 \% & 6 & 17 \%\end{array}$

\section{Discussion}

The optimal handling of the exocrine secretion in pancreatic transplantation has been much debated. As already mentioned, several techniques other than enteric drainage have been used to handle the exocrine secretion of the pancreatic graft. One reason for this was the high incidence of exocrine fistulas and infections encountered with enteric drainage in the early cases. Today most groups favour exocrine drainage to the recipient's bladder, as advocated by Sollinger et al. (1985). With such drainage the risk of bacterial contamination is reduced. Moreover, monitoring of the amylase excretion from the pancreatic graft, as reflected by the amylase level in the patient's urine, has been found useful in the diagnosis of rejection. However, some characteristic disadvantages with the bladder drainage technique have also emerged. These include urinary tract pathology and chronic metabolic acidosis, secondary to the loss of the alkaline pancreatic secretions via the bladder (Nghiem et al. 1987; Munda et al. 1987).

Diversion of the exocrine secretions to the bowel is obviously the most physiological technique. Initially the results with this technique were poor, but with refinements in the surgical procedure and with the application of a pancreatic duct catheter for temporary protection of the pancreatico-enteric anastomosis the incidence of exocrine leakage was greatly reduced (Groth et 
al. 1982; Tydén et al. 1987). With the use of pancreaticoduodenal grafts the anastomosis needed for enteric drainage has been reduced to a simple bowel-to-bowel anastomosis and the risk of enteric leakage has been more or less eliminated. Indeed, in the present series of pancreaticoduodenal transplantations the entero-enterostomy anastomosis was considered to be so safe that the usual Roux-en-Y loop was omitted after the first seven cases, and in the latest 18 cases the duodenum was simply anastomosed side-to-side to the jejunum (Tydén et al. 1990). Although the enteric anastomosis was considered safe, a pancreatic duct catheter was used to divert the exocrine secretion to the exterior for the first few weeks. This permits monitoring of the pure pancreatic secretion. The amylase content and the cytology of the exteriorized juice are important markers for pancreatic graft rejection episodes (Brattström et al. 1987; Reinholt et al. 1988). This is of special importance when the pancreas alone is transplanted. In patients who receive simultaneous renal and pancreatic grafts the diagnosis of rejection can usually be based on renal markers. When the ductal catheter has been removed the diagnosis of rejection in the patients with a pancreatic graft alone must, however, rely on serum markers. We have shown that serum levels of pancreas specific protein (procarboxypeptidase B) (Fernstad et al. 1989) and anodal trypsin (Brattström et al. 1989) have a high correlation with inflammatory events in the pancreatic graft. However, these findings require further confirmation.

Most groups, including our own, have performed mostly pancreatic transplantation as a procedure ancillary to renal transplantation in diabetic patients with end-stage renal disease. By so doing we largely circumvent the question as to whether it is justifiable to expose the diabetic patient to a surgical procedure which is to be followed by chronic immunosuppression. The recent marked improvement in the results of combined renal and pancreatic transplantation has, however, made us decide to offer pancreatic transplantation also to non-uraemic diabetic patients. Further support for this change in policy has been provided by the finding that the vascular lesions in the diabetic patient with end-stage renal disease are not reversed, and perhaps not even halted, by pancreatic transplantation (Solders et al. 1987; Ramsay et al. 1988), a finding probably explicable by the fact that the secondary lesions in these patients are too far advanced to be affected. At present, however, the results with pancreatic transplantation alone are similar to those obtained with combined transplantation a few years ago. Graft function is lost for various reasons, including some of the well-known technical complications. Moreover, chronic rejection, which is uncommon in recipients of combined grafts in uraemic recipients, is responsible for most of the single pancreatic graft failures (Tydén et al. 1990). Apparently this procedure also requires a learning phase.

\section{References}

Brattström C, Tydén G, Malmborg A-S, Ost L, Groth CG (1987) Studies of the exocrine secretion of segmental pancreatic grafts with special reference to the diagnosis of rejection and to the penetration of drugs into the pancreatic juice. Transplant Proc 19:2332-2335

Brattström C, Tydén G, Reinholt F, et al (1989) Markers for pancreas graft rejection in humans. Diabetes 38 Suppl 1: $57-62$

Fernstad R, Sköldefors H, Pousette $\AA$, et al (1989) A novel assay for pancreatic cellular damage. Use of a pancreasspecific protein as a marker of pancreatic graft dysfunction in humans. Pancreas 4:44-52

Groth CG, Lundgren G, Amer P, Collste H, Hårdstedt C, Lewander R (1976) Rejection of isolated pancreatic allografts in patients with diabetes. Surg, Gynecol, Obstet 143:933- 940

Groth CG, Lundgren G, Östman J, Gunnarsson R (1980) Experience with 9 segmental pancreatic transplantation in pre-uremic diabetic patients. Transplant Proc 12 Suppl 2:68-72

Groth CG, Collste H, Lundgren G, et al (1982) Successful outcome of segmental human pancreatic transplantation with enteric exocrine diversion after modification in technique. Lancet II:522-524

Munda R, Tom W, Fürst MR, Gartside R, Alexander JW (1987) Pancreatic allograft exocrine urinary tract diversion: Pathophysiology. Transplantation 43:95-99

Nghiem DD, Gonva TA, Corry RJ (1987) Metabolic effects of urinary diversion of exocrine secretion in pancreas transplantation. Transplantation 43:70-73

Ramsay RC, Goetz FC, Sutherland DER, Mauer M, Robinson L, Cantrill H, Knobloch W, Najarian J (1988)

Progression of diabetic retinopathy after pancreas transplantation for insulin-dependent diabetes mellitus. N Engl J Med 318:208-214

Reinholt F, Tydén G, Bohman S-O, Brattström C, Groth CG (1988) Pancreatic juice cytology in the diagnosis of pancreatic graft rejection. Clin Transplant 2:127-133

Solders G, Wilczek H, Tydén G, Gunnarsson R, Persson A, Groth CG (1987) Effects of combined pancreatic and renal transplantation on diabetic neuropathy. A two year follow up study. Lancet II :1232-1235

Sollinger HW, Kalayougly H, Hoffman R, Bezer FO (1985) Results of segmental and pancreatico-cystostomy. Transplant Proc 17:360-362

Tydén G, Wilczek H, Lundgren G, Ostman J, Gunnarsson R, Jaremko G, Groth CG (1985) Experience with 21 intraperitoneal segmental pancreatic transplantations with enteric or gastric diversion in man. Transplant Proc 17:331-335

Tydén G, Brattström C, Lundgren G, Östman J, Gunnarsson $\mathrm{R}$, Groth CG (1987) Improved results in pancreatic transplantation by avoiding non-immunological graft failures. Transplantation 43:674-676

Tydén G, Tibell A, Groth CG (1991) Pancreatico-duodenal transplantation with enteric exocrine drainage. Technical aspects. Clin Transplant 5:36-39

Tydén G, Tibell A, Bolinder J, Östman J, Groth CG (1990) High incidence of late rejections in pre-uremic recipients of pancreas transplants either provided aloneor in combination with renal transplants. Transplant Proc 22:1582-1583

Dr. G. Tydén

Department of Transplantation Surgery

Huddinge Hospital

S-141 86 Huddinge

Sweden 